\title{
Sierra Leone - investing in nutrition to reduce poverty: a call for action
}

\author{
Victor M Aguayo ${ }^{1, *}$, Sylvetta Scott ${ }^{2}$ and Jay Ross $^{3}$ on behalf of the PROFILES Study Group in \\ Sierra Leone† \\ ${ }^{1}$ Regional Nutrition and Child Survival Advisor for Africa, Helen Keller International, Rue 555/27, \\ Quinzambougou, BP E-1557, Bamako, Mali: ${ }^{2}$ Head of Nutrition, Ministry of Health and Sanitation, Freetown, \\ Sierra Leone: ${ }^{3}$ Policy Coordinator, LINKAGES Project, Academy for Educational Development, Washington, \\ DC, USA
}

Submitted 17 October 2002: Accepted 7 May 2003

\begin{abstract}
Background: Malnutrition rates in Sierra Leone are among the highest in the world. However, policy-makers do not always recognise the fight against malnutrition as a policy priority to ensure the healthy human capital needed to fight poverty and achieve sustained positive economic growth.

Objective: The analysis presented here was conducted by an intersectoral and interagency group of Sierra Leonean senior policy advisors to quantify some of the potential human and economic benefits of improved policies and programmes to reduce malnutrition.

Findings: The analysis revealed that $46 \%$ of child deaths in Sierra Leone are attributable to malnutrition, the single greatest cause of child mortality in the country. In the absence of adequate policy and programme action, malnutrition will be the underlying cause of an estimated 74000 child deaths over the next five years. The analysis also revealed that if current levels of iodine deficiency remain unchanged over the next five years, 252000 children could be born with varying degrees of mental retardation as a result of intrauterine iodine deficiency. Finally, the analysis showed that, in the absence of adequate policy and programme action to reduce the unacceptable rates of anaemia in women, the monetary value of agricultural productivity losses associated with anaemia in the female labour force over the next five years will exceed $\$ 94.5$ million.

Conclusion: Sustained investment in nutrition in Sierra Leone could bring about enormous human and economic benefits to develop the social sector, revitalise the economy, and attain the poverty reduction goals that Sierra Leone has set forth.
\end{abstract}

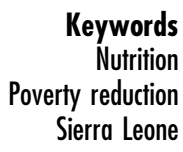

Despite Sierra Leone's vast endowment of human and natural resources, the country suffers from endemic and pervasive poverty due to long periods of economic decline and mismanagement. The 10-year civil war has further exacerbated the depth and severity of poverty.

†Ayodele Cream-Wright (Ministry of Finances); Alusine Callon (Ministry of Agriculture, Forestry and Marine Resources); Joseph W Jackson (Ministry of Trade, Industries and State Enterprises); Paul R Margai (Ministry of Youth, Education and Sports); Marie Chantal Messier (Helen Keller International); Hawa A Musa (Ministry of Development and Economic Planning); Solomon Scott (Ministry of Development and Economic Planning); Gabriel M Sellu (Ministry of Youth, Education and Sports); Paul A Sengeh (United Nations Children's Fund (UNICEF)); M'Balu Fatmata Sesay (National Commission for Social Action); Teresa A Vamboi (Ministry of Social Welfare, Gender and Children's Affairs); Mohamed K Warritay (Ministry of Finances); Adriana Zarrelli (UNICEF).
As a result, current development indicators in Sierra Leone are among the worst in the world ${ }^{1}$. Now that the transition from war to peace has been completed with the first democratic elections (May 2002), the Government's priority is to fight poverty, improve the living conditions of the most vulnerable in the population and achieve sustained economic growth. To reach these goals, the Government is developing a Poverty Reduction Strategy Paper that will outline the Government's objectives, policies and programmes to strengthen the social sector and revitalise the economy, while promoting participation and good governance ${ }^{2}$.

Malnutrition rates in Sierra Leone are among the highest in the world ${ }^{3}$. However, policy-makers, decision-makers, programme planners, opinion leaders and the news media do not always recognise the fight against malnutrition as a policy priority to ensure the healthy human capital 
Sierra Leone needs for sustained economic growth and poverty reduction. In view of this situation, the Ministry of Health and Sanitation in Sierra Leone, with the technical support of Helen Keller International and the United Nations Children's Fund, organised a two-week workshop on nutrition policy analysis and advocacy using PROFILES analytical and communications tools.* This analysis was conducted by an intersectoral and inter-agency group of Sierra Leonean senior policy advisors representing the Ministry of Agriculture, Forestry and Marine Resources, the Ministry of Development and Economic Planning, the Ministry of Finances, the Ministry of Health and Sanitation, the Ministry of Social Welfare, Gender and Children's Affairs, the Ministry of Trade, Industries and State Enterprises, the Ministry of Youth, Education and Sports and the National Commission for Social Action.

The analysis covered the period from 2002 to 2006, the five years following the democratic elections that took place in May 2002. The objective of the analysis was to quantify: (1) the consequences of malnutrition on human capital and productivity; and (2) the potential benefits of improved policies and programmes to reduce malnutrition. This paper presents some of the main findings of the analysis and shows how feasible, affordable and costeffective interventions can contribute to achieve the poverty reduction and economic development goals that Sierra Leone has set forth.

\section{Nutrition and health}

Childhood mortality is one of the best indicators of a country's development. In Sierra Leone, infant and child mortality rates are the highest in the world: one infant in six dies in the first year of life and one child in four dies before the age of five ${ }^{3}$. Child malnutrition is widespread in Sierra Leone. A recent survey shows that $27 \%$ of Sierra Leonean under-fives are underweight ${ }^{4}$. This means that their weight is too low for their age, their immune system is weak, their ability to fight infection and disease is compromised, and their risk of premature death is high.

Unquestionable epidemiological evidence shows that there is a clear link between malnutrition and child mortality. A meta-analysis of the findings of eight studies in five countries (Bangladesh, Cameroon, India, Malawi and Papua New Guinea) showed that the risk of death in children under 5 years of age increases exponentially (i.e. by a multiplicative factor) as underweight becomes more severe $^{5}$. Children with mild, moderate or severe underweight are respectively $2.5,4.6$ or 8.4 times more likely to die than children whose weight-for-age is within the normal range. The proportion of child mortality

*PROFILES is a data-based approach to nutrition policy analysis and advocacy originally developed under the Nutrition Communication Project managed by the Washington-based Academy for Educational Development. attributable to malnutrition in Sierra Leone (or population attributable risk, PAR) was calculated as:

$$
\sum \mathrm{PAR}_{i}=\frac{\mathrm{PREV}_{i} \times\left(\mathrm{RR}_{i}-1\right)}{1+\left[\mathrm{PREV}_{i} \times\left(\mathrm{RR}_{i}-1\right)\right]}
$$

where $\mathrm{RR}_{i}$ is the relative risk of death for children in a given underweight category (mild, moderate or severe) and $\mathrm{PREV}_{i}$ is the prevalence of underweight for the same given category. The PARs for the three different underweight categories were summed to calculate the total PAR of mortality to child underweight in Sierra Leone.

The analysis revealed that $46 \%$ of child deaths are attributable to malnutrition (measured as underweight) in Sierra Leone, making malnutrition the single greatest cause of child mortality in the country. In other words, in the absence of adequate policy and programme action, 74000 child deaths over the next five years will be attributable to underweight (i.e. in the absence of underweight, these children would not die). Four in five of such deaths will be attributable to mild and moderate forms of underweight that are 'hidden and silent', as the victims and their caregivers seldom recognise the warning signs.

In Sierra Leone, child malnutrition starts very early in life due to sub-optimal infant feeding practices. Following international guidelines, the Ministry of Health and Sanitation in Sierra Leone recommends that infants be exclusively breast-fed from birth to about 6 months of age. However, 98\% of 0- to 5-month-old infants in Sierra Leone are given water, fluids and foods ${ }^{4}$. This harmful practice exposes infants to pathogens and increases the risk of malnutrition and death. At about 6 months of age, infants need to be fed adequate complementary foods. Locally available foods rich in energy, protein and micronutrients should be the basis of complementary feeding. In Sierra Leone, $48 \%$ of 6- to 9-month-old infants are not fed any complementary foods ${ }^{4}$ and therefore lack nutrients essential for survival, growth and development. Sub-optimal feeding practices in early childhood explain the progressive increase of malnutrition levels in Sierra Leonean children in the first two years of life (Fig. 1). By the age of 2 years most of the damage to children's health, growth and development is done, and the chances of recovery are minimal.

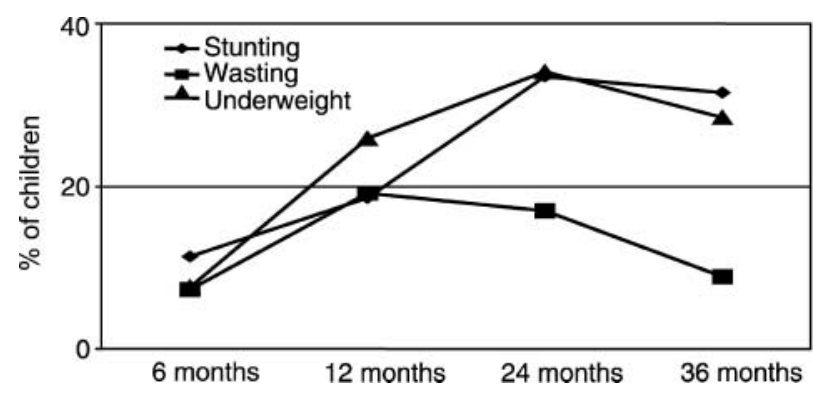

Fig. 1 The evolution of child malnutrition with age in Sierra Leone. Source: Multiple Indicators Cluster Survey II, $2000^{4}$ 
Much of the functional damage resulting from malnutrition in early childhood is due to deficiencies in micronutrients such as vitamin A. A meta-analysis of eight population-based intervention trials assessing the contribution of vitamin A deficiency to child mortality showed that, in areas where vitamin A deficiency is prevalent, child mortality can be reduced by an average of $23 \%$ following vitamin A repletion ${ }^{6}$. This significant reduction in childhood mortality is explained to a great extent by a reduction in mortality from measles ${ }^{7}$, severe diarrhoea and dysentery $^{8}$, and possibly falciparum malaria ${ }^{9}$. It is estimated that the risk of death in vitamin A-deficient children is 1.75 times higher than in vitamin A-sufficient children $^{10}$. In Sierra Leone, an estimated $40 \%$ of underfives suffer from vitamin A deficiency ${ }^{11}$. The proportion of child mortality attributable to vitamin A deficiency in Sierra Leone (or PAR) was calculated as:

$$
\operatorname{PAR}_{\mathrm{a}}=\frac{\operatorname{PREV}_{\mathrm{a}} \times\left(\mathrm{RR}_{\mathrm{a}}-1\right)}{1+\left[\operatorname{PREV}_{\mathrm{a}} \times\left(\mathrm{RR}_{\mathrm{a}}-1\right)\right]},
$$

where $R_{a}$ is the relative risk of death in vitamin $A$ deficient children relative to vitamin A-sufficient children and $\mathrm{PREV}_{\mathrm{a}}$ is the estimated prevalence of vitamin $\mathrm{A}$ deficiency. The analysis reveals that in the absence of appropriate and sustained policy and programme action to control vitamin A deficiency in the next five years, over 38000 deaths of Sierra Leonean children under 5 years of age will be attributable to vitamin A deficiency.

\section{Nutrition and economic growth}

Adequate nutrition is essential for the mental development of children. Scientific evidence from different countries shows that malnutrition reduces children's learning ability, school performance and retention rates ${ }^{12}$. Iodine deficiency is a good example of how the consequences of malnutrition on children's mental development can manifest themselves even before birth. Iodine is essential for brain development in the foetus. Based on research findings by Clugston et $a l .{ }^{13}$, Burkhalter estimated that $3 \%$ of babies born to iodine-deficient women suffer from cretinism and 10\% suffer from severe mental retardation ${ }^{14}$. Moreover, there is evidence that the remaining infants born to mothers with goitre also suffer an intellectual deficit due to the brain damage resulting from intrauterine iodine deficiency. A meta-analysis of over 20 studies on the links between iodine deficiency and cognitive development showed that, in populations where iodine deficiency is endemic, the IQ of children is reduced by an average of 13.5 points $^{15}$.

In Sierra Leone, sub-clinical iodine deficiency is thought to be widespread: an estimated $25 \%$ of women of reproductive age suffer from goitre, a clinical sign of iodine deficiency ${ }^{16}$, and only $23 \%$ of households have access to adequately iodised salt ${ }^{4}$. Our analysis showed that if current levels of iodine deficiency in women of reproductive age remain unchanged, an estimated 7500 children born over the next five years will suffer from cretinism, 25200 will be severely mentally impaired and 219300 will present mild forms of mental retardation. This means that a total of 252000 newborns will have varying degrees of mental retardation due to intrauterine iodine deficiency.

The community-wide impairment in intellectual functioning due to intrauterine iodine deficiency has serious consequences on productivity. It is estimated that individuals who suffer from cretinism have no productivity and that severely mentally impaired individuals (due to iodine deficiency) are $25 \%$ less productive than unaffected individuals ${ }^{14}$. Moreover, children born to mothers with goitre who are neither cretins nor severely mentally impaired will grow to be $5 \%$ less productive than unaffected children ${ }^{17}$. Our analysis showed that if current levels of iodine deficiency in Sierra Leone remain unchanged over the next five years, the present value of the future productivity losses associated with the intellectual impairment resulting from intrauterine iodine deficiency exceeds $\$ 42.5$ million.*

Stunting also has an immense impact on the future productivity of children $^{18}$. In Sierra Leone, $31.5 \%$ of children are stunted by the age of 35 months $^{3}: 16.4 \%$ of children in this age group suffer from moderate stunting (height-for-age between -2 and -3 standard deviations (SD) from the median of the reference population) and $15.1 \%$ suffer from severe stunting (height-for-age $<-3 \mathrm{SD})$. Assuming that these deficits are irreversible, children with moderate and severe stunting by age 35 months will have an average adult height that is $4.4 \%$ and $6.3 \%$ lower, respectively, than that of individuals whose height-for-age at age 35 months was within the normal range (between $-2 \mathrm{SD}$ and $+2 \mathrm{SD})^{19}$. This reduced adult height is associated with a $1.4 \%$ loss in productivity for each $1 \%$ loss in adult height ${ }^{20}$. In our analysis we assumed that $16.4 \%$ of Sierra Leonean children suffer from moderate stunting by age 35 months and that these children will suffer an average height loss in adulthood of $4.4 \%$ that leads to an average productivity reduction of $6.2 \%$ $(4.4 \times 1.4)$. We also assumed that $15.1 \%$ of Sierra Leonean children suffer from severe stunting by age 35 months and that these children will suffer an average height loss in adulthood of $6.3 \%$ that leads to an average productivity reduction of $8.7 \%(6.2 \times 1.4)$. We have assumed that productivity losses in adulthood resulting from stunting in early childhood are limited to the most-labour demanding sectors (agriculture, fishery, mining and heavy industry), which represent $77 \%$ of the employed population ${ }^{21}$.

*The economic analysis presented in this paper accounts for current rates of malnutrition, mortality, employment and labour force participation. An internationally accepted 3\% annual discount rate has been applied to estimate the net present value of future productivity losses resulting from malnutrition. 
Taking all of these parameters into account our analysis showed that if current levels of stunting in children remain unchanged over the next five years, the net present value of the productivity losses resulting from stunting in early childhood exceeds $\$ 41.5$ million.

Maternal anaemia increases the likelihood of maternal death. It is estimated that anaemia is the underlying cause of $20 \%$ of maternal deaths in sub-Saharan Africa ${ }^{22}$. In Sierra Leone, an estimated $68 \%$ of women of reproductive age are anaemic. The consequences of women's anaemia on agricultural productivity are staggering. Available epidemiological evidence shows that the productivity of adult anaemic individuals is reduced by $1.5 \%$ for every $1 \%$ decrease in haemoglobin $(\mathrm{Hb})$ concentration below the threshold normally used for the definition of anaemia $\left(120 \mathrm{gl}^{-1} \text { in non-pregnant women }\right)^{17}$. In our analysis we assumed that a sixth of anaemic women in Sierra Leone suffer from severe anaemia $\left(\mathrm{Hb}<70 \mathrm{gl}^{-1}\right)$, a third suffer from moderate anaemia $\left(70 \mathrm{gl}^{-1}<\mathrm{Hb}<90 \mathrm{gl}^{-1}\right)$ and half suffer from mild anaemia $\left(90 \mathrm{gl}^{-1}<\mathrm{Hb}<120 \mathrm{gl}^{-1}\right)$. To be conservative, we assumed that there is a reduction in productivity of only $1 \%$ for every $1 \%$ reduction in $\mathrm{Hb}$ concentration below $120 \mathrm{~g} \mathrm{l}^{-1}$. Assuming that $75 \%$ of Sierra Leonean women of reproductive age are engaged in agricultural productivity ${ }^{20}$, our analysis showed that if adequate policy and programme action is not taken to reduce the unacceptable rates of anaemia in women in Sierra Leone, the economic value of agricultural productivity losses associated with anaemia in the female labour force over the next five years will exceed $\$ 94.5$ million. This needs to be considered a conservative estimate of the potential impact of anaemia on female productivity, as it assumes that women's productivity in sectors other than the agricultural sector is not affected by anaemia.

\section{Investing in nutrition: the way forward}

Our analysis suggests an urgent need for policy and programme action. A renewed and sustained political commitment, both nationally and internationally, is needed to improve the nutrition situation of Sierra Leonean children and women, and avoid a tragic and irreversible loss of human capital. To this effect, the following proven, cost-effective, high-impact nutrition actions must be given policy and programme priority in the context of the Poverty Reduction Strategy Paper development in Sierra Leone.

\section{Protect, promote and support optimal child feeding practices in the first two years of life}

To this effect, national policies and programmes need to ensure that:

1. Optimal breast-feeding practices are protected, promoted and supported in health facilities, communities and workplaces.
2. National legislation regulating the marketing of breast milk substitutes is developed and enacted.

3. National guidelines on infant feeding options are developed for women living with HIV/AIDS and all health personnel are trained on the appropriate application of such guidelines.

4. Optimal complementary feeding practices beginning at about 6 months are protected, promoted and supported through facility- and community-based growth monitoring and promotion interventions.

\section{Ensure that the vitamin A requirements of the population are met}

To this effect, national policies and programmes need to:

1. Promote the initiation of exclusive breast-feeding immediately after birth so that infants can take full advantage of the high vitamin A content of colostrum.

2. Ensure that all children aged 6-59 months are supplemented with a high-potency vitamin A capsule (200 000 IU) biannually.

3. Ensure that vitamin A supplementation is incorporated into the routine integrated management of childhood illnesses.

4. Ensure that all women receive one dose of vitamin A (200 $000 \mathrm{IU})$ as soon as possible after delivery and not later than 8 weeks' post delivery.

5. Promote the consumption of locally available vitamin A-rich foods.

6. Explore the feasibility of vitamin A fortification of widely consumed foods.

\section{Ensure that the iron and folic acid requirements of the population are met}

To this effect, national policies and programmes need to:

1. Ensure that all pregnant women and women in early postpartum receive daily iron $(60 \mathrm{mg})$ and folic acid $(400 \mu \mathrm{g})$ supplements as well as adequate counselling on the use of such supplements.

2. Ensure that all pregnant women are dewormed during the second trimester of pregnancy.

3. Ensure that all pregnant women receive one course of treatment for malaria and a weekly preventive dose throughout pregnancy.

4. Ensure that all pregnant women sleep under impregnated bed nets.

5. Develop and implement a comprehensive strategy for the control of anaemia in children that integrates iron deficiency control, parasite control and malaria control.

6. Promote the consumption of locally available iron-rich foods.

7. Explore the feasibility of iron fortification of widely consumed foods. 


\section{Ensure that the iodine requirements of the population are met}

To this effect, national policies and programmes need to ensure that all salt for human and animal consumption, whether imported or locally produced, is fortified with adequate levels of iodine and that the consumption of iodised salt is promoted in a sustained manner.

\section{Conclusion}

Our analysis shows that a sustained investment in nutrition in Sierra Leone would avoid thousands of deaths of children and women, a tragic lowering of the intellectual capacity and enormous economic losses. Three conditions need to be met for the attainment of these benefits. The first is that adequate nutrition be recognised as a prerequisite for poverty reduction and economic growth in Sierra Leone; the second condition is that the political commitment to improving the nutritional status of the population be unambiguous and sustained; and the third is that nutrition and nutrition-relevant policies and programmes target the most vulnerable groups through cost-effective interventions. This unambiguous, sustained, targeted and cost-effective investment in nutrition will bring about enormous benefits for health, education and productivity. The attainment of these benefits will be an indicator of good governance and the only hope of attaining the poverty reduction goals that Sierra Leone has set forth.

\section{References}

1 United Nations Development Programme. Deepening Democracy in a Fragmented World. Human Development Report, 2002. New York: Oxford University Press, 2002.

2 Ministry of Development and Economic Planning, Republic of Sierra Leone. Interim Poverty Reduction Strategy Paper. Freetown: Ministry of Development and Economic Planning, Republic of Sierra Leone, 2001.

3 United Nations Children's Fund (UNICEF). State of the World's Children 2002. New York: UNICEF, 2002.

4 United Nations Children's Fund (UNICEF). Sierra Leone: Multiple Indicators Cluster Survey II (MICS-II). Freetown: UNICEF, 2000.

5 Pelletier DL, Frongillo EA Jr, Schroeder DG, Habicht JP. A methodology for estimating the contribution of malnutrition to child mortality in developing countries. Journal of Nutrition 1994; 124: 2106S-22S.

6 Beaton GH, Martorell R, Aronson KJ, Edmonston B, McCabe $\mathrm{G}$, Ross AC, et al. Effectiveness of Vitamin A Supplementation in the Control of Young Child Morbidity and Mortality in Developing Countries. United Nations Administrative
Committee on Coordination/Sub-committee on Nutrition (ACC/SCN) State-of-the-art Series: Nutrition Policy Discussion Paper No. 13. Geneva: ACC/SCN, 1993.

7 Barclay AJ, Foster A, Sommer A. Vitamin A supplements and mortality related to measles: a randomised clinical trial. British Medical Journal 1987; 294: 294-6.

8 Arthur P, Kirkwood B, Ross D, Morris S, Gyapong J, Tomkins A, et al. Impact of vitamin A supplementation on childhood morbidity in northern Ghana. Lancet 1992; 339: $361-2$.

9 Shankar AH, Genton B, Semba RD, Baisor M, Paino J, Tamja $\mathrm{S}$, et al. Effect of vitamin A supplementation on morbidity due to Plasmodium falciparum in young children in Papua New Guinea: a randomised trial. Lancet 1999; 354: $203-9$.

10 Ross JS. Derivation of the Relative Risk of Child Mortality due to Vitamin A Deficiency. PROFILES Working Notes Series No. 2. Washington, DC: Academy for Educational Development, 1996.

11 Micronutrient Initiative (MI)/United Nations Children's Fund (UNICEF)/Tulane University (TU). Progress in Controlling Vitamin A Deficiency. Ottawa: MI/UNICEF/TU, 1998.

12 Jukes M, McGuire J, Method F, Sternberg R. Nutrition and education. In: United Nations Administrative Committee on Coordination/Sub-committee on Nutrition (ACC/SCN), ed. Nutrition: A Foundation for Development. Geneva: ACC/SCN, 2002.

13 Clugston GA, Dulberg EM, Pandav CS, Tiden RL. Iodine deficiency disorders in South East Asia. In: Hetzel BS, Dunn JT, Stanbury JB, eds. The Prevention and Control of Iodine Deficiency Disorders. Amsterdam: Elsevier, 1987; 65-84.

14 Burkhalter BR. The Structure and Models used in PROFILES 2.O. Washington, DC: Academy for Educational Development, 1994.

15 Bleichrodt N, Born MP. A meta-analysis of research on iodine and its relationship to cognitive development. In: Stanbury JB, ed. The Damaged Brain of Iodine Deficiency. New York: Cognizant Communication Corporation, 1994.

16 Maternal and Child Health Division. National Survey on Iodine Deficiency Disorders. Freetown: Maternal and Child Health Division, 1993.

17 Levin HM, Pollitt E, Galloway R, McGuire J. Micronutrient deficiency disorders. In: Jamison DT, Mosley WH, eds. Disease Control Priorities in Developing Countries. New York: Oxford University Press, 1993.

18 Martorell R. The role of nutrition in economic development. Nutrition Reviews 1996; 54: S66-71.

19 Pinstrup-Andersen P, Burger S, Habicht JP, Peterson K. Protein-energy malnutrition. In: Jamison DT, Mosley WH, eds. Disease Control Priorities in Developing Countries. New York: Oxford University Press, 1993.

20 Haddad LJ, Bouis HE. The impact of nutritional status on agricultural productivity. Wage evidence from the Philippines. Oxford Bulletin of Economics and Statistics 1991; 53(1): 45-68.

21 Islamic Development Bank (IDB). Sierra Leone Feasibility Study. Freetown: IDB, 1994.

22 Ross JS, Thomas EL. Iron Deficiency Anemia and Maternal Mortality. PROFILES Working Notes Series No. 3. Washington, DC: Academy for Educational Development, 1996. 